\title{
Design e Avaliação de um Aplicativo Móvel de Notificações para Interações em Fóruns em LMS
}

\author{
João Marcelo Pontes Ferraz ${ }^{1}$, Ivanildo José de Melo Filho ${ }^{2,3}$, Luma da Rocha \\ Seixas $^{3}$, Alex Sandro Gomes ${ }^{3}$ \\ ${ }^{1}$ Universidade Federal de Pernambuco (UFPE) \\ Programa de Pós-Graduação em Comunicação - PGCOM \\ ${ }^{2}$ Instituto Federal de Pernambuco (IFPE) - Campus Paulista \\ ${ }^{3}$ Universidade Federal de Pernambuco (UFPE) - Centro de Informática (CIn) \\ jm.ferraz@gmail.com, ivanildo.melo@paulista.ifpe.edu.br, \\ lrs3ecin.ufpe.br, asg@cin.ufpe.br
}

\begin{abstract}
This article aims to present the development, prototyping and testing of a mobile application to notify about activities carried out in forums in the LMS Moodle environment. The context in which this research was developed at the Federal Institute of Pernambuco (IFPE) in distance technical training courses. The procedure for its development consisted of four phases namely: immersion, prototyping, experiment and analysis. The results obtained from the perception of the participants allowed to evolve and improve the changes in the interface of the application during the immersions, generating an experience of suitable use for the learners of this modality of teaching.
\end{abstract}

Resumo. Este artigo tem como objetivo apresentar o desenvolvimento, prototipação e teste de um aplicativo móvel para notificar sobre atividades realizadas em fóruns no ambiente LMS Moodle. O contexto no qual esta pesquisa foi desenvolvida no Instituto Federal de Pernambuco (IFPE) em cursos de formação técnica a distância. O procedimento para seu desenvolvimento consistiu em quatros fases, a saber: imersão, prototipação, experimento e análise. Os resultados obtidos a partir da percepção dos participantes permitiram evoluir e aprimorar as mudanças na interface do aplicativo no decorrer das imersões, gerando uma experiência de uso adequada para os aprendizes dessa modalidade de ensino.

\section{Introdução}

Os elementos de percepção social em um LMS são mecanismos criados para auxiliar na construção e manutenção de consciência sobre as atividades, contexto ou situação dos usuários que compartilham o mesmo ambiente, mesmo quando estes não se encontram conectados ao sistema no momento [MARKOPOULOS, RUYTER e MACKAY, 2009]. Tais mecanismos de percepção social são fundamentais para a existência de colaboração entre os participantes, pois, ao fomentar as relações sociais e atualizar os usuários sobre os acontecimentos no ambiente compartilhado, estimulam as ações dos mesmos [KUSHWAHA, 2013]. 
Dentre os recursos disponíveis nos ambientes LMS, um dos mais utilizados são os fóruns de discussão. Estes, são espaços compartilhados que promovem debates coletivos e abertos no qual qualquer aprendiz do curso pode ler e interagir em uma plataforma de construção coletiva [MERCADO e ARAÚJO, 2010]. Tais interações enriquecem os debates realizados e evidenciam a diversidade de pontos de vista [CONOLE, 2013; HAMDAN, 2014].

Além disso, tais interações coletivas incentivam os aprendizes a aprender para dialogar, ao mesmo tempo que o ato do diálogo os faz aprender por si [MICHINOV et al., 2011; BAXTER e HAYCOCK, 2014]. Para Cavus e Zabadi (2014), os fóruns de discussão são categorizados como ferramentas de comunicação/aprendizagem, nos quais os dois atos são correlatos. Porém, para que esta comunicação seja possível é necessário existir a percepção das movimentações que ocorrem nesses espaços. Um dos LMS mais utilizados atualmente é o Moodle. Este possui um aplicativo móvel, contudo, não realiza notificações sobre as movimentações nos fóruns. Dessa forma, esta pesquisa apresenta a prototipação e teste de um aplicativo móvel que realiza notificações sobre atividades realizadas em fóruns no LMS Moodle.

Este artigo está organizado da seguinte forma: A seção 2 é apresentado o resultado de um levantamento bibliográfico sobre percepção social em fóruns de LMS. A seção 3 é descrito o processo metodológico utilizado na pesquisa e, na sequência, a seção 4 apresenta os resultados do experimento, junto com uma análise dos resultados. E, por fim a seção 5, traz as considerações finais sobre o trabalho.

\section{Percepção Social e Notificações em Fóruns de LMS}

Os elementos de percepção social em um LMS são mecanismos criados para auxiliar na construção e manutenção de consciência sobre as atividades, contexto ou situação dos usuários que compartilham o mesmo ambiente, mesmo quando estes não se encontram conectados ao sistema no momento [MARKOPOULOS, RUYTER e MACKAY, 2009]. Estes mecanismos de manutenção de percepção social são fundamentais para a existência de colaboração entre os participantes, pois ao fomentar as relações sociais, atualizando os usuários sobre os acontecimentos no ambiente compartilhado, estimula naturalmente as ações dos mesmos [KUSHWAHA, 2013]. Estabelecendo respectivamente, uma relação de causa e efeito entre percepção social e interação dos usuários no espaço virtual compartilhado.

Esta relação causal entre percepção (social) e a interação (social) é investigada por Rittenbruch e McEwan (2009). Os autores apontam que a segunda é alcançada apenas após a consciência gerada pela primeira, consequentemente, a percepção é necessária para haver interação. Isso porque é a partir de um entendimento compartilhado do estado de coisas no ambiente que os usuários se mobilizam em um trabalho de colaboração [GEROSA, FUKS \& LUCENA, 2003]. Portanto, para existir criação coletiva é necessária a participação dos envolvidos. Por conseguinte, tal participação é incentivada em decorrência da percepção dos acontecimentos no espaço virtual compartilhado [MANTOVANI, BACKES \& SANTOS, 2012]. Estas interações devem ficar claras para os usuários por meio de notificações. 
As notificações são cruciais para manter os aprendizes cientes dos acontecimentos em fóruns. Segundo pesquisa de Luo et al. (2014), os próprios aprendizes alegam a necessidades de mecanismos de notificações de interações em LMS. Os mecanismos de informações de percepção (awareness information) são agentes notificadores das mudanças ocorridas no espaços compartilhados, contidos nos LMS. Essas notificações informam o aprendiz, com intuito de produzir percepção do espaço de trabalho. Estes mecanismos de notificação são utilizados para representar interações em âmbito síncrono e assíncrono, status de objetos compartilhados, progresso de tarefas colaborativas, envio de arquivos, entre outros [ECHEVERRÍA, COBOS \& MORALES, 2014].

As interações em fóruns de discussão cabem na classificação de "interações em âmbito assíncrono", com conteúdo de notificações para manter o aprendiz informado sobre as últimas postagens no ambiente. Portanto, notificar é uma forma explícita de manter a percepção social dos aprendizes. Além disso, para que os aprendizes interajam nos fóruns eles precisam estar cientes dos acontecimentos nesse ambiente compartilhado. Esta relação causal entre percepção e interação estudada por Echeverría, Cobos e Morales (2014) é fundamental para o entendimento da importância das notificações nesse contexto. Tais notificações têm como conteúdo elementos informacionais de aspectos sociais, de percepção assíncrona e de modificações no espaço de trabalho, já que a cada introdução de conteúdo em um fórum, este é modificado automaticamente.

Para os autores as notificações de atividades de fóruns dão suporte a diferentes tipos de percepção. A Percepção Social (Social Awareness) - Conhecimento sobre as relações dentro do grupo no que concerne às atividades do curso. A Percepção de Tarefas (Tasks Awareness) - Entendimento de como os usuários completam as tarefas, como as tarefas serão executadas. A Percepção de Grupo (Group Awareness) - É mantida a partir da informação sobre como os participantes de um grupo de trabalho estão executando suas atividades. A Percepção do Espaço de Trabalho (Workspace Awareness) - Consciência sobre as interações entre os aprendizes dentro do ambiente compartilhado e as mudanças deste ambiente e dos objetos disponíveis para interação.

\section{Método}

O processo metodológico planejado e aplicado durante o desenvolvimento desta pesquisa possui cunho qualitativo e indutivo e segue as recomendações de Flick (2009) e Malheiros (2011). Levando em consideração aspectos ergonômicos, cognitivos e contextuais, o paradigma de desenvolvimento de protótipo posto em prática foi o User Experience Design (UX Design), um ramo do design focado na experiência do usuário final, projetando artefatos que resolvam seus problemas e propiciem boa usabilidade. A seguir são apresentadas as fases do processo de UX design, adaptado à pesquisa, junto a uma breve descrição das técnicas utilizadas em todo o percurso para o desenvolvimento desse trabalho.

\subsection{Primeira Fase - Imersão}

O objetivo dessa fase foi entender a relação causal entre alguns aspectos de percepção 
social e a interação de aprendizes nos fóruns do Moodle, e quais fatores mantém esta percepção. Os participantes nessa fase foram 08 (oito) aprendizes da disciplina de Eletrônica Básica do curso Técnico de Manutenção e Suporte em Informática a Diretoria de Educação a Distância (DEAD) do Instituto Federal de Pernambuco (IFPE). Esta etapa iniciou-se com o intuito de compreender a relação dos alunos com os fóruns do Moodle e de como eles atuam nestes.

Para tal imersão acompanhou-se os aprendizes por um período de três meses as interações da turma nos fóruns a partir da técnica de netnografia [KUNIAVISKY; 2010]. Para auxiliar a netnografia foi utilizada a aplicação web, Social Networks Adapting Pedagogical Practice (SNAPP) [BAKHARIA e DAWSON, 2011], que nos possibilitou extrair informações sobre quantas vezes cada aluno interagiu no fórum e caso tenha ocorrido alguma interação diretamente com algum aprendiz seria possível saber com quem e quantas vezes ocorreu a interação.

$\mathrm{Na}$ sequência, os aprendizes foram entrevistados de forma semiestruturada, a partir de um tópico-guia, baseado em Bauer e Gaskell (2002), que objetivou abordar suas experiências formais de aprendizado anteriores, relação com tecnologia, com a turma, com o curso e com os fóruns disponíveis em cada disciplina no LMS.

\subsection{Segunda Fase: Prototipação}

Considerando necessidades/requisitos identificados na Fase 01, foi esboçado o primeiro protótipo de interface em mockup. Esta foi testada por meio de um teste de usabilidade e compreensão baseado em Krug (2001). Duas rodadas de teste e avaliação foram realizadas. Devido à limitação do tempo e disponibilidade dos participantes, bem como, das diretrizes demandadas pela Instituição ABC, nesta fase, a avaliação dos protótipos foi realizada por aprendizes diferentes dos que participaram na fase de imersão (Fase 01).

$\mathrm{Na}$ primeira rodada, 08 (oito) usuários participaram desse teste e os resultados obtidos permitiram identificar a necessidade de maior refinamento dos protótipos. Em um novo ciclo de concepção, uma nova versão de interface foi desenvolvida e o primeiro aplicativo funcional para dispositivos Android foi concebida. Nesse momento, uma segunda rodada de avaliação e teste foi realizado por meio de um teste piloto com 06 (seis) aprendizes de outras turmas. Seis aprendizes utilizaram o aplicativo por 08 (oito) dias para a detecção e eventuais problemas de uso e de ergonomia.

\subsection{Terceira Fase: Experimento}

O experimento durou três meses, 08 (oito) aprendizes instalaram o aplicativo em seus celulares e receberam um diário de campo, recomendado por Sáez (2013), para anotarem detalhes da rotina de uso da aplicação. Durante o experimento os fóruns foram analisados netnograficamente. Após os três meses de uso todos os diários foram analisados e, posteriormente, os aprendizes foram entrevistados sobre o impacto da aplicação em sua experiência. 


\subsection{Quarta Fase: Análise}

Ao fim do experimento, foram analisadas as entrevistas, os diários e as interações em fóruns. Para a análise do conteúdo levantado utilizamos o Método Lógico-Semântico, pelo qual foi inferido o conteúdo expresso em comentários, registros e relatos e os relacionamos com o fenômeno observado no experimento [MALHEIROS, 2011]. Para, assim, ser possível balizar possíveis reflexões sobre causas e consequências da percepção social no contexto observado e como o protótipo funcional interferiu na formação dessa percepção nos participantes. Os relatos, anotações em diários e sugestões dos aprendizes foram traduzidos em uma nova geração de requisitos para o desenvolvimento de uma nova proposta de interface ao fim da pesquisa.

\section{Resultados e Discussão}

Nesta seção são descritos e discutidos os resultados relacionados a cada fase que permitiu que todas as ações relacionadas ao desenvolvimento do aplicativo de notificações pudessem ser incorporadas em seu processo de design.

Na Fase 01 - Imersão, foi possível observar nos aprendizes uma insatisfação com o curso, com a experiência junto ao LMS e com os seus fóruns, em particular em relação à baixa percepção destes quanto às atividades nos fóruns. Durante a netnografia isso também foi percebido nos fóruns. Havia um intervalo muito grande entre as interações e, no geral, um baixo engajamento entre os aprendizes. Foram evidenciados problemas no tocante às notificações do sistema. Como afirmado por Luo (et al., 2014) e ratificado nos resultados das entrevistas com os aprendizes, é evidente a necessidade dos aprendizes serem notificados sobre os acontecimentos nos fóruns em ambientes virtuais de aprendizagem. Nesse sentido, o procedimento aplicado foi capaz de captar diversas evidências relacionadas às notificações que foram detalhadas pelos usuários.

Em relação à percepção dos participantes sobre as notificações no ambiente em sua tela inicial foi possível identificar duas situações. O aprendiz A5 afirmou nunca ter sido notificado ao longo do curso, enquanto os demais aprendizes perceberam as notificações do sistema em sua página inicial, porém ressaltaram a pouca evidência das notificações na interface. A respeito da janela de notificações, ao clicar nela o usuário é levado a uma página com notificações. Porém, os aprendizes reclamaram da ausência de detalhamento destas, visto que as mensagens assíncronas de mensagens e fórum estão agrupadas no mesmo local. Além disso, segundo os entrevistados, o entendimento da notificação seria simplificado se a interface dividisse as informações por disciplina, com dados que criassem percepção sobre o estágio das atividades, do grau de movimentação e do assunto tratado nos fóruns, separando explicitamente cada o tema de cada fórum.

É possível confirmar isto na fala do aprendiz A7: "As notificações são imprecisas. Você devia receber tudo já pronto, já ficar sabendo o que tá tendo no fórum. Além do que, já perco muito tempo só de ter que entrar no Moodle pra ver se tem algo novo lá. Porque tenho que entrar pra ver." Complementando este cenário, o aprendiz A3 revela que: "Às vezes entro no site só pra saber se tem coisa nova, pra não perder nada importante. Mas na maioria das vezes não tem ou tem umas conversas que 
não são importantes. Me sinto perdendo tempo". Posteriormente o aprendiz A3 narrou um episodio em que esta dificuldade de acesso às notificações acarretou em um problema para ele: "Eu sempre entrava no Moodle, todos os dias[...] Mas uma vez eu tava muito ocupado e passei três dias sem entrar. Quando eu vi, tava em cima do prazo de uma atividade e tive que correr atrás pra fazer. Me atrapalhou muito".

Ao longo das entrevistas, foi levantado junto aos aprendizes indicadores para a manutenção da percepção destes quanto aos acontecimentos nos fóruns do Moodle. Os relatos usados para enumerar os requisitos do protótipo confirmam as observações do quadro de Echeverría, Cobos e Morales (2014), pois de modo geral os aprendizes apontaram direta ou indiretamente para quatro elementos informacionais: identidade (quem?), local (onde?), ação (o que?) e interação (quando?). Tais elementos são fundamentais para gerar "Percepção do Espaço de Trabalho" e, por consequência, "Percepção de Grupo", cuja correlação é apontada por Gutwin e Greenberg (2002) e comentada no mesmo capítulo. A partir destes elementos, os aprendizes passam a ter uma noção de contexto para sentirem-se informados e incentivados a interagir. No caso, o protótipo concebido informa qual aprendiz interagiu, apontando em qual fórum e quando essa interação ocorreu, além de exibir os primeiros cem (100) caracteres escritos na mensagem.

Durante a Fase 02 - Prototipação que ocorreu após entrevistas com os aprendizes e compreender o contexto problemático em relação a percepção das atividades nos fóruns e a partir dos elementos informacionais de percepção para notificações compilados por Echeverría, Cobos e Morales (2014), Identidade (Quem?), Local (Onde?), Ações (O Que?), Processos (Como?) e Interações (Quando?); desenvolvemos uma interface, neste caso, um protótipo em forma de mockup com a interface de login e a página de notificações, conforme representadas por meio das Figuras 1 e 2 .

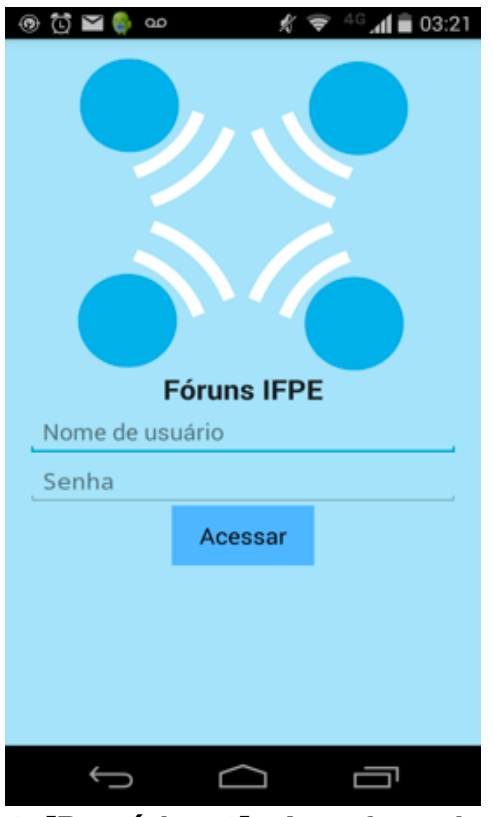

Figura 1. [Protótipo 1] - Interface de Login.

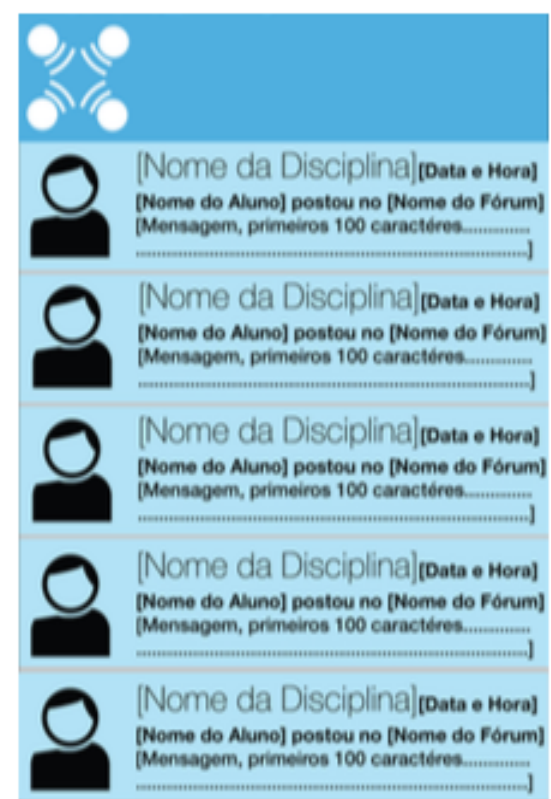

Figura 2. [Protótipo 2] - Interface de Notificações. 
A interface apresentada por meio da Figura 01 contém informações meramente ilustrativas. Para o teste foram impressas interfaces com trechos de fóruns pertinentes aos aprendizes participantes do teste. Ex.: Resposta do tutor a uma postagem própria ou comentário de outro aprendiz fazendo menção ao comentário do aprendiz participante do Teste de Compreensão. Portanto, o teste de usabilidade não tentou auferir aspectos de navegabilidade e sim a efetividade da interface ao informar sobre os acontecimentos nos fóruns. Para tanto, foi decidido a concepção de uma interface "leve", limpa e com design flat, dando destaque às notificações. O feedback recebido após o teste foi similar entre os aprendizes. Dentre os pontos destacados, observa-se: (1) perceberam a imagem do perfil como desnecessária, até porque a maioria dos usuários não utilizam imagem de perfil na plataforma, eles argumentaram que apenas o nome do usuário seria suficiente para identificação, (2) na primeira proposta apresentada, as notificações divididas e apresentadas por fóruns (ex. notificações do fórum 1, notificações do fórum 2...).

Entretanto, foi unânime o interesse em uma ordenação apenas temporal, não levando em consideração o fórum na ordenação. Seguindo o feedback dos alunos foi desconsiderado a permanência da identificação do usuário - Vide Figura 3 - e a concepção da nova interface ajustada, conforme pode ser visto por meio da Figura 4. Após o teste dessa segunda interface três usuários classificaram a forma de disposição das notificações como ruim.

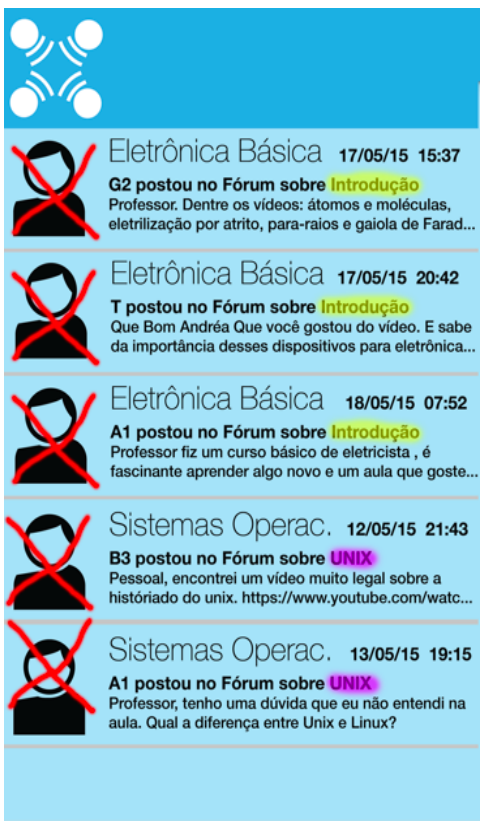

Figura 3. [Protótipo 3] Interface de Notificações Avaliada.

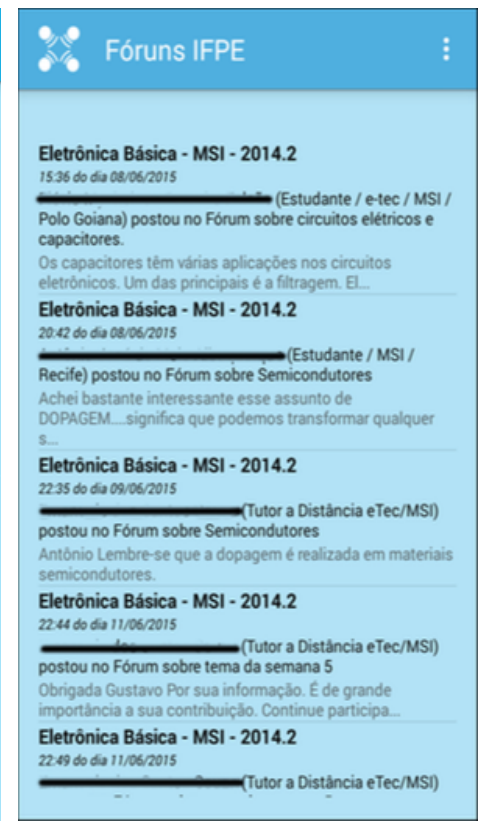

Figura 4. [Protótipo 4] Interface de Notificações Ajustada.

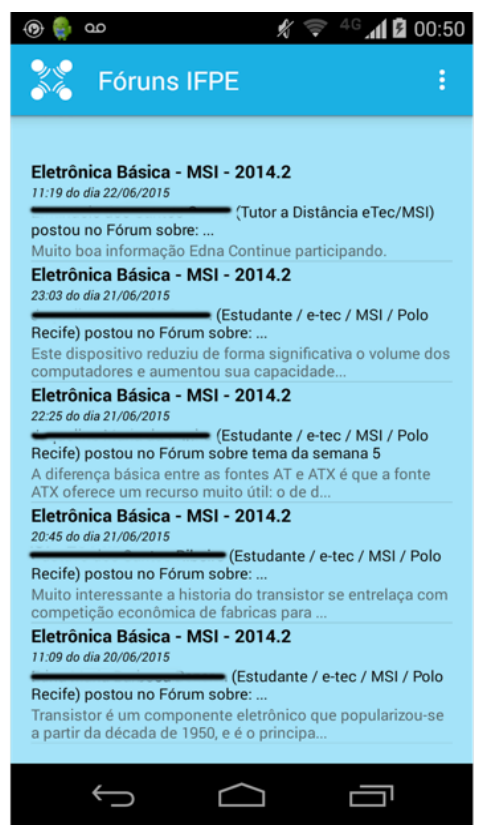

Figura 5. [Protótipo 5] Interface de Notificações com Campos Reordenados.

A ordem das notificações causava confusão e atrapalhava a leitura da interface. A aplicação ao fazer a requisição do HTML da página do Moodle, organizava as notificações na ordem em que eram apresentadas no fórum, de cima para baixo. Ou seja, mostrando da notificação "mais antiga" a "mais recente". Os autores Bodemer e Dheler 
(2011), Tam e Greenberg (2006) e Gutwin e Greenberg (2001) alertam que para a notificação criar e manter a percepção social e de espaço de trabalho é prioritário o conhecimento sobre os acontecimentos mais recentes, de modo que estes devem ficar em evidência na interface. Acompanhando esse feedback a ordem das notificações foi invertida. O terceiro protótipo - Vide Figura 5 - assim como o segundo ordena as notificações levando em consideração a data e a hora da interação. Todavia, enquanto o segundo organiza do mais antigo ao mais recente o terceiro protótipo faz o inverso, colocando as interações mais recentes no topo da lista de notificações.

A Fase 03 - Experimento contou com a participação de 08 (oito) aprendizes. A maioria dos aprendizes - A1, A4, A5, A6 e A8 - manteve a mesma média de postagens em fóruns. Todavia, entre a análise das entrevistas e dos diários foram percebidas mudanças na experiência desses com os fóruns que não puderam ser observadas a partir da análise dos fóruns. Os demais aprendizes apresentaram um maior engajamento nos fóruns, durante o experimento. A aprendiz A2, ao explicar o aumento de sua participação nos fóruns durante o experimento, nos revela que: "Ficou fácil pra mim saber quando tinha que comentar no fórum, o aplicativo não me deixava esquecer. Chegava do trabalho, jantava e já ia lá escrever". Neste contexto, podemos compreender que a proximidade do smartphone com o aprendiz ao longo de sua jornada diária mostrou-se fundamental para o aumento das interações de A2. Por sua vez, o aprendiz A7 apresentou uma mudança de comportamento ainda maior. Este aprendiz interagiu nos fóruns da disciplina apenas após a instalação do protótipo. Em entrevista, ele nos confessa que: “...como é virtual não tem ninguém lá fiscalizando. É um ensino praticamente autodidata, porque não tem ninguém ali em cima de você. $O$ incentivo parte de você mesmo".

O aprendiz também nos revelou que traça um pouco seu perfil de aprendizado com foco maior no material didático que no AVA em si: "Tem gente que entra todo dia, eu já não sou esse aluno. Eu seleciono bastante. Baixo a apostila e fico focado nela. Só depois de um tempo eu vou lá ver os fóruns. Deixo acumular pra ler". Porém, no diário é percebido que o protótipo o tornou mais consciente dos acontecimentos do fórum, fazendo-o participar das discussões no Moodle. No diário de A7 há uma rotina, a qual apresentamos a seguir. "Dia 30/06 - Almoço - Recebi notificação dos fóruns de Transistor e AT e ATX. Cheguei em casa. Jantei e Li os fóruns, escrevi sobre a diferença da fonte AT e ATX”. Ao falar de sua experiência com as notificações via smartphone, A7 comenta: "O impacto que ele causou foi justamente trazer essa praticidade da atualização das informações pro meu dia. Ele fez com que as interações fossem sentidas realmente, me fazendo ler os novos comentários pouco tempo depois deles terem sido postados. [...] O projeto do aplicativo é uma ideia muito boa. É uma ótima maneira de você perceber as interações de forma mais rápida. A pessoa fica mais segura quanto a o que tá acontecendo no Moodle. Então, eu ia acompanhando e quando já tinha coisa acumulada eu fui lá comentar”.

A Fase 04 - Análise permitiu a concepção da proposta final organizamos as modificações sugeridas pelos usuários e apresentamos uma nova interface para o protótipo. O Quadro 1 mostra as sugestões de modificações (M) sugeridas pelos aprendizes participantes do experimento, para serem consideradas na criação do 
protótipo final da pesquisa.

\section{Quadro 1 - Modificações Sugeridas pelos Participantes.}

\begin{tabular}{|c|c|c|c|}
\hline Item & Sugestão de Modificação & $\begin{array}{c}\text { Tipo de } \\
\text { Percepção }\end{array}$ & Fonte \\
\hline M1 & $\begin{array}{l}\text { Atualização Manual das } \\
\text { Notificações }\end{array}$ & (Operacional) & Não identificado. \\
\hline M2 & Exibir Comentário Inteiros & Informação & (TAM e GREENBERG, 2006) \\
\hline M3 & Chat & Social & $\begin{array}{l}\text { (BODEMER e DEHLER, 2011; ECHEVERRÍA, } \\
\text { COBOS \& MORALES 2014) }\end{array}$ \\
\hline M4 & Calendário do Curso & Tarefa & \multirow[t]{3}{*}{ (GROS et al., 2005) } \\
\hline M5 & Notificar Envio de Arquivo & Tarefa & \\
\hline M6 & Questionário & Tarefa & \\
\hline M7 & $\begin{array}{l}\text { Notificar Abertura de Novo } \\
\text { Fórum }\end{array}$ & $\begin{array}{l}\text { Espaço de } \\
\text { Trabalho }\end{array}$ & $\begin{array}{l}\text { (GUTWIN et al., 2008; LAMBROPOULOS e } \\
\text { CULWIN, 2010) }\end{array}$ \\
\hline M8 & Mensagens da Coordenação & Informação & \multirow[t]{2}{*}{ (TAM e GREENBERG, 2006) } \\
\hline M9 & Notas de Provas e Atividades & Informação & \\
\hline M10 & $\begin{array}{l}\text { Diminuir Tempo de } \\
\text { Atualização Automática }\end{array}$ & (Operacional) & Não identificado. \\
\hline M11 & $\begin{array}{l}\text { Notificar Sobre Fórum que } \\
\text { Aprendiz não Interagiu }\end{array}$ & $\begin{array}{c}\text { Tarefa e } \\
\text { Social } \\
\end{array}$ & $\begin{array}{l}\text { (GROS et al., 2005), (BODEMER e DEHLER, 2011; } \\
\text { ECHEVERRÍA, COBOS \& MORALES, 2014) }\end{array}$ \\
\hline M12 & Imagens dos Usuários & Social & $\begin{array}{l}\text { (BODEMER e DEHLER, 2011; ECHEVERRÍA, } \\
\text { COBOS \& MORALES, 2014) }\end{array}$ \\
\hline M13 & $\begin{array}{l}\text { Destacar Comentários de } \\
\text { Professor ou Tutor }\end{array}$ & Social & Não identificado. \\
\hline M14 & Nível de Interação nos Fóruns & $\begin{array}{c}\text { Tarefa e } \\
\text { Social }\end{array}$ & $\begin{array}{l}\text { (GROS et al., 2005), } \\
\text { (BODEMER e DEHLER, 2011; ECHEVERRÍA, } \\
\text { COBOS \& MORALES, 2014) }\end{array}$ \\
\hline
\end{tabular}

As Figuras 6, 7 e 8 exibem a proposta de interface, marcando as modificações sugeridas pelos usuários descritas no Quadro 1.

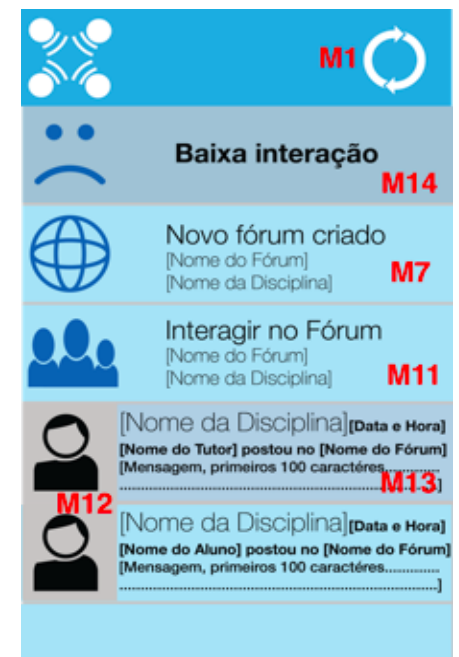

Figura 6. [Protótipo 6] - Interface de Notificações - Versão Final.

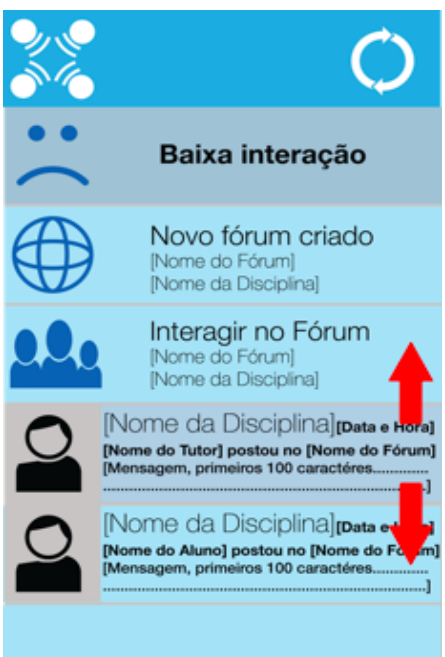

Figura 7. [Protótipo 7] Expandir Comentário 1.

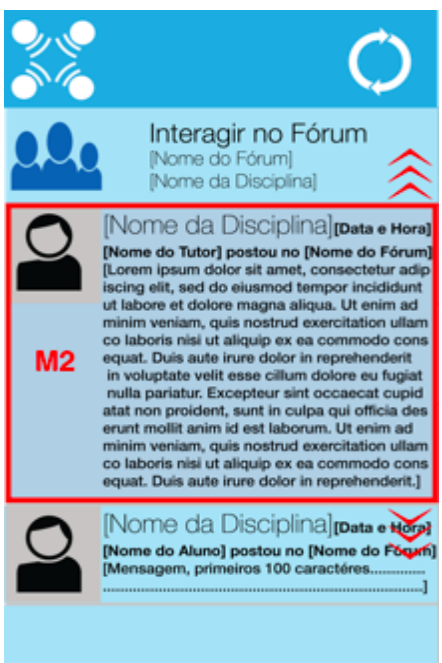

Figura 8. [Protótipo 8] Expandir Comentário 2.

Como é possível perceber as versões propostas da interface foram marcadas com 
letras e números vermelhos sinalizando cada modificação contida do Quadro 1 nas Figuras 6 e 7. Na Figura 8 é representada a interação para "abrir" a notificação, para a leitura do comentário na íntegra, exibindo na interface o comentário expandido, referente a M2.

\section{Considerações Finais}

O presente trabalho apresentou conceitos sobre percepção social em ambientes virtuais de aprendizagem para basear uma pesquisa de cunho qualitativo por meio do design centrado no usuário para o desenvolvimento de um aplicativo de notificação para fóruns em LMS. Os resultados obtidos com esta pesquisa, após a imersão no contexto com aprendizes pelo uso de diários e entrevistas narrativas, nos mostraram a importância da percepção dos usuários para a interação destes em fóruns de AVA. Nas coletas com os aprendizes foi possível ratificar a relação causal vista na literatura. Além de confirmar os fatores de manutenção desta percepção.

O protótipo funcional, tem seu funcionamento apenas nas versões do Android $4.0 \mathrm{ou}$ superior. Este fator limitante existe pelo fato dessas versões Android mais recentes serem completamente diferentes das anteriores, o que geraria o dobro de esforço em desenvolvimento para fazer com que o protótipo rodasse em todas as versões. O mesmo é verdade sobre os outros sistemas operacionais como Windows Phone OS e iOS. Para desenvolver corretamente para cada sistema operacional seria necessário um esforço que não se justifica para um teste de protótipo. Neste momento, - um experimento encontra-se em processo de planejamento com a proposta de interface, com um número maior de aprendizes, quantidade suficiente para extrair dados qualitativos confiáveis, possibilitando a extrapolação dos resultados estatísticos.

\section{Referências}

BAKHARIA, A.; DAWSON, S. SNAPP: A Bird's-Eye View of Temporal Participant Interaction. LAK'11. Banff, 2011.

BAUER, M. W e GASKELL, G., 2002. Pesquisa Qualitativa com Texto, Imagem e Som: um manual prático. Editora Vozes, Petrópolis. Brasil. BAXTER, J. A.; BODEMER, D., \& DEHLER, J. Group awareness in CSCL environments. Computers in Human Behavior. Elsevier, 2011.

HAYCOCK, J. Roles and Students Identities in Online Large Course Forums: Implications for Practice. The International Review of Research in Open and Distance Learning, Vol. 15 No.1. Athabasca University, 2014.

CAVUS, N.; ZABADI, T. A Comparison of Open Source Learning Management Systems. Procedia: Social and Behavioral Sciences, 2014.

CONOLE, G. Designing for Learning in an Open World. Explorations in the Learning Sciences. Intructional Systems and Performance Technologies. Springer, 2013.

ECHEVERRIA, L.; COBOS, R.; MORALES, M. A Notification Manager to support collaborative learning in LMS Moodle. IEEE Global Engineering Education Conference (EDUCON). Instanbul, Turkey, 2014. 
FLICK, Uwe. Introdução à Pesquisa Qualitativa. Porto Alegre: ARTMED, 2009.

GEROSA, M.A.; FUKS, H.; LUCENA, C.J.P. Suporte à Percepção em Ambientes de Aprendizagem Colaborativa. Revista Brasileira de Informática na Educação, Vol. 11, No. 2. Sociedade Brasileira de Computação, 2003.

GUTWIN, C.; GREENBERG, S.; BLUM, R.; DYCK, J.; TEE, K.; MCEWAN, G. Supporting Informal Collaboration in Shared-Workspace Groupware. Journal of Universal Computer Science, vol. 14, no. 9, 2008.

HAMDAN, A. K. The Reciprocal and Correlative Relationship Between Learning Culture and Online Education: A Case from Saudi Arabia. The International Review of Research in Open and Distance Learning, Vol. 15 No.1. Athabasca University, 2014.

KUNIAVSKY, M. Smart Things: Ubiquitous Computer User Experience Design. Burlington: Morgan Kaufmann, 2010.

KUSHWAHA, R. C. Exploring student Engagement in Learning Management System. DST-Centre for Interdisciplinary Mathematical Sciences(DST-CIMS). Banaras Hindu University (BHU), Varanasi, INDIA, 2013.

KRUG, Steve. Não me faça pensar: Uma abordagem de bom senso à usabilidade na web. São Paulo: Market Books, 2001.

LUO, G.; LIU, E. Z.; KUO, H.; YUAN, S. Design and Implementation of a SimulationBased Learning for International Trade. The International Review of Research in Open and Distance Learning, Vol. 15 No.1. Athabasca University, 2014.

MALHEIROS, B. T. Metodologia da Pesquisa em Educação. LTC, Rio de Janeiro, 2011 .

MANTOVANI, A. M. ; BACKES, L. ; SANTOS, B. S. Formação Do Educador No Contexto Da Cibercultura: Possibilidades Pedagógicas Em Metaversos (Mundos Digitais Virtuais Em 3 Dimensões MDV3D. Contrapontos (UNIVALI) (Cessou em 2008. Cont. ISSN 1984-7114 Contrapontos (Online), v. 12, p. 77-86, 2012.

MARKOPOULOS, P.; RUYTER, B.; MACKAY, W. Awareness Systems: Advances in Theory, Methodology, and Design. Human-Computer Interaction. Series - Springer, 2009.

MERCADO, L. P. L.; ARAÚJO, R. S. Letramento Digital nas Interações On-Line: Análise dos Fóruns de Discussão do Programa de Formação Continuada em Mídias na Educação. RBEP, V. 91, N. 227. Brasiíia, 2010.

MICHINOV, N.; BRUNOT, S.; LE BOHEC, O. JUHEL, J.; DELAVAL, M. Procrastination, Participation and Performance in Online Learning Environments. Computers and Education, 56. Elsevier, 2011.

RITTENBRUCH, M., MCEWAN G. An Historical Reflection of Awareness in Collaboration. Chapter 1 - Awareness Systems - Advances in Theory, Methodology, and Design - Human-Computer Interaction Series - Markopoulos, P., Ruyter, B. de, Mackay, W. Springer. 2009. 
SÁEZ, O. C. Esse Obscuro Objeto da Pesquisa: Um manual de método, técnicas e teses em antropologia. Ilha de Santa Catarina, 2013.

TAM, J.; GREENBERG, S. A framework for asynchronous change awareness in collaborative documents and workspaces. Int. J. Human- Computer Studies Vol. 64, pp. 583-598, 200. 